\title{
Effect of deep frying process using sesame oil, canola and frying oil on the level of bioactive compounds in onion and potato and assessment of their antioxidant activity
}

\author{
Nasim NIKZAD ${ }^{1}$ (D), Mehrdad GHAVAMI ${ }^{1 *}$, Mahdi SEYEDAIN -ARDABILI ${ }^{1}$, Behrouz AKBARI-ADERGANI², \\ Reza AZIZINEZHAD ${ }^{3}$
}

\begin{abstract}
In this study, potatoes and onions were fried in sesame oil, canola oil and commercial frying oil at $180{ }^{\circ} \mathrm{C}$ for 8 and 4 minutes respectively. The process was performed at three steps. Fried potatoes and onions were evaluated by the measurements of parameters such as fatty acid, tochopherols. The results showed that in terms of changes in fatty acid profile in fried samples, the linolenic acid content in sesame and canola has been decreasing. The highest levels of tocopherol were found in fried samples of sesame oil. Finally, it can be concluded that sesame oil has been shown to be better in terms of resistance to other oils studied in this study.
\end{abstract}

Keywords: antioxidant; bioactive compounds; deep frying; phenolic compounds.

Practical Application: Select the best oil for deep frying technology.

\section{Introduction}

One of the popular, convenient and quick process to prepare food is frying technique (Borjian Borojeni et al., 2016). Despite the negative attitude towards fried foods in diet concerned with calorie, cholesterol and saturated fat content, frying is a delicious method to provide foods with good texture, taste and color (Ghidurus et al., 2010) and palatability also improve the nutritional quality of foods. Frying might be caused out in two ways; shallow frying and deep drying. Deep frying is one of the most prevalent methods. The purpose of deep frying is to immerse the food at high temperature (150 to $190{ }^{\circ} \mathrm{C}$ ), so quality, taste and flavors of the final products will be improved (Choe \& Min, 2007). The quality of food prepared by this method not only depends on the frying conditions, such as temperature and time of frying, food weight, methods of frying, presence of antioxidant, type of food and oil used (Choe \& Min, 2007; Serjouie et al., 2010) selection of proper oil, due to the absorption in the final products, can affect the nutrition quality of the foods (Chiou et al., 2009; Borjian Borojeni et al., 2016). According to the WHO recommendation, the composition of fatty acids in the daily diet should include $50 \%$ of saturated fatty acids, $40 \%$ of monounsaturated fatty acids and less than $10 \%$ of polyunsaturated fatty acids (Nikzad et al.,2013).

During deep frying several reactions such as hydrolysis, oxidation, polymerization and isomerization might occur due to the presence of some factors mainly high temperatures, oil, air and water. These reactions have influence on the nutritional properties of the oil (Serjouie et al., 2010; Sedaghat Boroujeni \& Hojjatoleslamy, 2018).
Oxidation of oils during food storage and processing not only leads to a loss of nutritional value and digestive quality of food, but also leads to the production of oxidized products such as free radicals. Free radicals produced in food cause spontaneous oxidation and the production of undesirable chemical compounds and the development of many diseases, especially cancer (Gol Ahmad et al, 2019).

Resistance to oxidative rancidity might be considered as one of the important factor concerned with frying oils. Sesame oil due to its popularity and presence of natural antioxidants namely sesamol and tocopherols (Yen \& Shyu, 1989) has been considered as a healthy oil in Asian countries (Nzikou et al., 2009). The oil is used in food and cosmetic products due to its high oxidative stability (Borjian Borojeni et al., 2016). Compounds such as sesamin, sesamolin and sesamol have physiological functions and can decrease blood lipids, increase anti-oxidative ability, and act as anti-inflammatory (Wu, 2007; Bakhtiary et al., 2014).

Canola (Brassica napus) is another best oilseed crops that is used as healthy oil. This oil is low in erucic acid and glucosinolates and is different in terms of chemical, physical and nutritional properties as compared to high erucic acid rapeseed oil (Beig Mohammadi et al., 2012).

Two of the most important vegetables crops are onions and potatoes in the world. In terms of taste and flavor, onion (Allium cepa) has special position foods, and the popularity of onion is not only due to their consumption as a flavor agent but also to their healthy, nutritional and functional properties 
(Petropoulos et al., 2015). Potatoes (Solanum tuberosum) have the high demand for consumption in the world (Bakhtiary et al., 2014). Potatoes are good source of nutrients and contain fiber, minerals and vitamins (Burlingame et al., 2009). Due to high consumption of potatoes, they are considered as a good source of ascorbic acid that act as vitamin $\mathrm{C}$ and antioxidant (Farhoosh \& Esmaeilzadeh Kenari, 2009).

The effects of sesame oil and rice bran oil on canola oil during deep frying has been investigated by Reza Farhoush and Reza Esmaeilzadeh Kenari in 2009 The purpose of this study was to evaluate the effect of sesame oil and or rice bran oil on degradation of canola oil during deep frying. The tests consisted of the measurement of fatty acids composition using gas chromatography, peroxide value, acidity using the AOCS standard, polar compounds based on the method developed by Schulte. The results showed that the best frying time was obtained when canola oil was mixed with sesame oil and rice bran oil, at the ratio of 94: 3: 3, respectively.

In another study, the effect of sesame oil on the quality characteristics of frying oil during deep frying was investigated by Borjian Borojeni et al. (2016). In this research, sesame seeds were roasted and the oil was extracted. Commercial frying oil (CFO) was mixed with different concentrations of sesame oil (RSO) and then used for deep frying of potato chips. This process was carried out daily at $180{ }^{\circ} \mathrm{C}$ for 1 hour in five consecutive days. The performance of frying oil was evaluated by measuring different parameters such as peroxide value, oxidation strength index (OSI), total polar composition (TPC) and fatty acid profile. The results indicated that roasting has a significant positive effect on phenolic compounds (21 times) and oxidative stability (3.6 times) of sesame oil. During frying, TPC levels increased significantly. By increasing the concentration of RSO, the antioxidant capacity of the frying oil increased, although the commercial frying oil containing TBHQ had a higher activity than $30 \%$ RSO.

Bakhtiari has carried out studies on the sensory evaluation of potato chips sesame oil and palm olein oil and their mixture were used as frying oil in 2014. In this research work, sensory evaluation concerned with qualitative factors was applied. The results showed that the mixture of these two oils provides better stability during frying process.

The phytochemical compounds of onions and potatoes are influenced by the method for usage. Since both vegetables usually are consumed after cooking and frying, it is necessary to evaluate their bioactive compound after processing at high temperature. The aim of the present study is to evaluate the effect of three oils (canola oil, sesame oil and frying oil) on the quality of potato and onion during three stages of deep frying.

\section{Materials and methods}

All chemicals and reagents were purchased from Merck Chemical Company. Samples of white onions were prepared from local market and samples Agria potato were collected from Poldasht, west of Iran. The Sesame, canola and frying oils were obtained from local market in Tehran.

\subsection{Sample preparation}

Crude and fresh potatoes and onions were washed, dried, peeled and cut to suitable size. The oils were stored at room temperature. The producer for preparing the samples was deep frying.

\subsection{Frying technique}

Deep-frying was carried out at $180{ }^{\circ} \mathrm{C}$ for $4 \mathrm{~min}$ for onions and at $180^{\circ} \mathrm{C}$ for $8 \mathrm{~min}$ for potatoes (Ramírez-Anaya et al., 2015). The selected time for frying depended on the suitable color and texture of foodstuff. New samples of chopped potatoes and onions were poured into the oils previously used after 120 minutes of interruption and fried again under the same conditions. This procedure was carried out for the third time to study the changes occurring. The samples were then immediately refrigerated for further analysis.

\subsection{Moisture, fiber and fat content}

The moisture, fat, and fiber contents of the Samples were examined by AOAC methods (2007) (Ramírez-Anaya et al., 2015). For moisture content the samples were dried at $105{ }^{\circ} \mathrm{C}$, to a constant weight. The Soxhlet method was used for crude fat determination. Dietary fiber was determined by dilating the samples by followed by hydrolysis of proteins and starch (Farhoosh \& Esmaeilzadeh Kenari, 2009).

\subsection{Oil extract conditions}

After removing the surface oil, the slices of food fried were cut and dried in a vacuum oven at $50{ }^{\circ} \mathrm{C}$ for $12 \mathrm{~h}$. The dried samples were ground, weighed and then transferred into extraction thimbles that were placed in dry $250 \mathrm{~mL}$ round bottom flasks containing $50 \mathrm{~mL}$ of petroleum ether according to AOAC (Association of Official Analytical Chemists, 1995), the extraction of oil was carried out for $2 \mathrm{~h}$ by a soxhlet system and the solvent was evaporated by a rotary evaporator. The flasks containing the extracted oil were dried in an oven at $105 \mathrm{C}$ to constant mass. Oil contents were expressed as percentage (Pedreschi et al., 2008).

\subsection{Determination of total tocopherol}

Tocopherols were determined according to ISO standard number 9936 (ISO 9936: 2006) by the application of HPLC equipped with UV detector (Anon. 2006). This HPLC system consists of an auto injector, HPLC pump and a UV-Vis detector. Analyzing of the tocopherols was performed by injecting $100 \mu \mathrm{L}$ of diluted oil on the column $(4.6 \mathrm{~mm} \times 25 \mathrm{~cm}, 5 \mu \mathrm{m})$. The column was eluted with the mobile phase that were methanol:deionized water: butanol (90:6:4) and the flow rate was set at $1 \mathrm{~mL} . \mathrm{min}$. The effluent was monitored with the UV detector at $294 \mathrm{~nm}$ (Choe \& Min, 2007; Chung et al., 2004; Wegener et al., 2015).

\subsection{Fatty acids profile}

Fatty acids profile was obtained by methyl esterification of fatty acids and detected by gas chromatography (GC) according to Iranian National Standardization Organization with Nom: $13126-2 ; 13126-4$. For this, about $0.1 \mathrm{~g}$ of the oil sample was 
inserted in $2 \mathrm{~mL}$ of heptane and then was shaken. Then $0.2 \mathrm{ml}$ of $2 \mathrm{~N}$ methanolic potassium hydroxide was added and placed on the cap. In following, tightened the lid and shaken vigorously for 30 seconds. Then allow some time for the top layer to become transparent after the layers separated. The top layer, which contains methyl ester, was slowly overflowed and finally the heptane solution was suitable for injection into gas chromatography. A FID detector was used for detection of fatty acids (Anon, 2016).

\subsection{Antioxidant capacity}

The antioxidant activity was measured according to Molyneux way. The antioxidant activity was measured according to Molyneux (Molyneux, 2004; Sedaghat Boroujeni et al., 2013). Before each test, Methanolic solution of DPPH as stable free radical was prepared. To $1 \mathrm{~mL}$ of the DPPH solution, $5 \mu \mathrm{L}$ of the sample were added, then stirred and waited for $10 \mathrm{~min}$ at room temperature. Pure methanol was used as the control. After this time the absorbance at $\lambda=515 \mathrm{~nm}$ was recorded again. The decrease in absorbance recorded as the antioxidant activity. The radical scavenging activity was calculated using the following formula (Formula 1) (Molyneux, 2004; Sedaghat Boroujeni et al., 2013):

$\% D P P H$ remaining $=\left(A_{\text {sample }} / A_{\text {control }}\right) \times 100$

\subsection{Statistical analyses}

In this study, a statistical analysis was conducted by a two factors factorial experiment in a Completely Random Design (CRD) with three repetitions. ANOVA is used to analyze the data and the statistical software used was SPSS 22 and SAS 9.6.

\section{Results and discussion}

\subsection{Pre-frying step}

Table 1 presents the free fatty acid composition (FFA) of oils used where the predominant fatty acids are oleic acid, linoleic acid. Frying oil had high concentration of palmitic acid and indicating that the oil might be a mixture of vegetable oils where palm oil or one of the fractions might be present.

The result in Table 1 show that in all oils, in the pre-frying step, the highest amount of FAs belonged to oleic acid, linoleic acid, palmitic acid and stearic acid, but in sesame oil the highest amount of free fatty acids are linoleic acid, oleic acid, palmitic acid and stearic acid, respectively. In frying oil and canola oil the highest amount of FFAs are oleic acid, linoleic acid, palmitic acid and stearic acid, respectively.

The range of Palmitic acid was 5-25\%. These fresh oils were significantly different with regard to their $\mathrm{C} 16: 0$ content $(\mathrm{p}<0.01)$. The oils were ranked in decreasing order of C16:0 content as fallows; frying oil > sesame oil > canola oil.

Oleic acid is one of the most important FFAs in oils and the content range is $35-57 \%$ in these fresh oils. The oils were significantly different with regard to their C18:1c content $(\mathrm{p}<0.01)$.
The highest amount of this compound was observed in canola oil, followed by sesame oil and frying oil.

The range of linoleic acid was $22-40 \%$. These fresh oils were significantly different with regard to their C18:2c content $(\mathrm{p}<0.01)$. The highest amount of this FFA was measured in sesame oil and then frying oil and canola oil.

The range of saturated fatty acid (SFA) was 7.5-25\%. These fresh oils were significantly different with regard to their saturated fatty acids content $(\mathrm{p}<0.01)$. The highest amount of this component was found in frying oil, sesame oil and canola oil, respectively.

The range of unsaturated fatty acid (UFA) content was 64-81\%. The fresh oils were significantly different in UFA content $(\mathrm{p}<0.01)$. The higher amount of unsaturated fatty acids was found in canola oil, sesame oil and frying oil, respectively.

Beig Mohammadi et al. (2012), evaluated the Physicochemical Properties and Stability of Oil Extracted from Three Canola Cultivars Grown in Golestan Province of Iran. They released that oleic acid is the major fatty acid in canola oil and linoleic acid is the highest level of essential fatty acid. Also, Gruzdiene and Anelauskaite studied Chemical composition and stability of rapeseed oil produced from various cultivars grown in Lithuania. Similar results were obtained from their research. Farhoosh \& Esmaeilzadeh Kenari (2009) worked on Anti-Rancidity Effects of Sesame and Rice Bran Oils on Canola Oil during Deep Frying Their results for fatty acids in canola oil were similar to our results.

Gharby et al. (2015) determine the characteristic features of the oil content and composition of nutrients of sesame seeds grown in Morocco. The results showed that the major unsaturated fatty acids were linoleic acid (46.9\%) followed by oleic acid (37.4\%), while the main saturated fatty acid was palmitic acid (9.1\%).

Table 2 shows the content of total tochopherol in crude oils.

The range of total tochopherol was $237-320 \mathrm{mg} . \mathrm{kg}$. The fresh oils were significantly different in the total tochopherol content $(\mathrm{p}<0.01)$. The highest amount of total tochopherol was observed in sesame oil followed by frying oil and canola oil.

One of the most important factors that effect on quality of edible oils is oxidation. It makes undesirable changes in their properties such as sensory and nutritional characteristic. The antioxidant capacity of the oils was determined with the $\mathrm{DPPH}$. The range of DPPH in these fresh oils was between 47-62\%. The differences between canola oil, sesame oil and frying oil were significantly. The highest amount of DPPH was found in fresh sesame oil.

Table 3 shows the fat, moisture, fiber content and DPPH of crude potato and onion.

According Table 3, Amount of fat, moisture and fiber in fresh potato were $0.05 \%, 72.15 \%$ and $13.83 \%$ respectively.

Also, in crude onion the compounds were $0.03 \%, 89.04 \%$ and $4.18 \%$ respectively. So the highest amount of fat, moisture and fiber are corresponded to potato, onion and potato, respectively. 


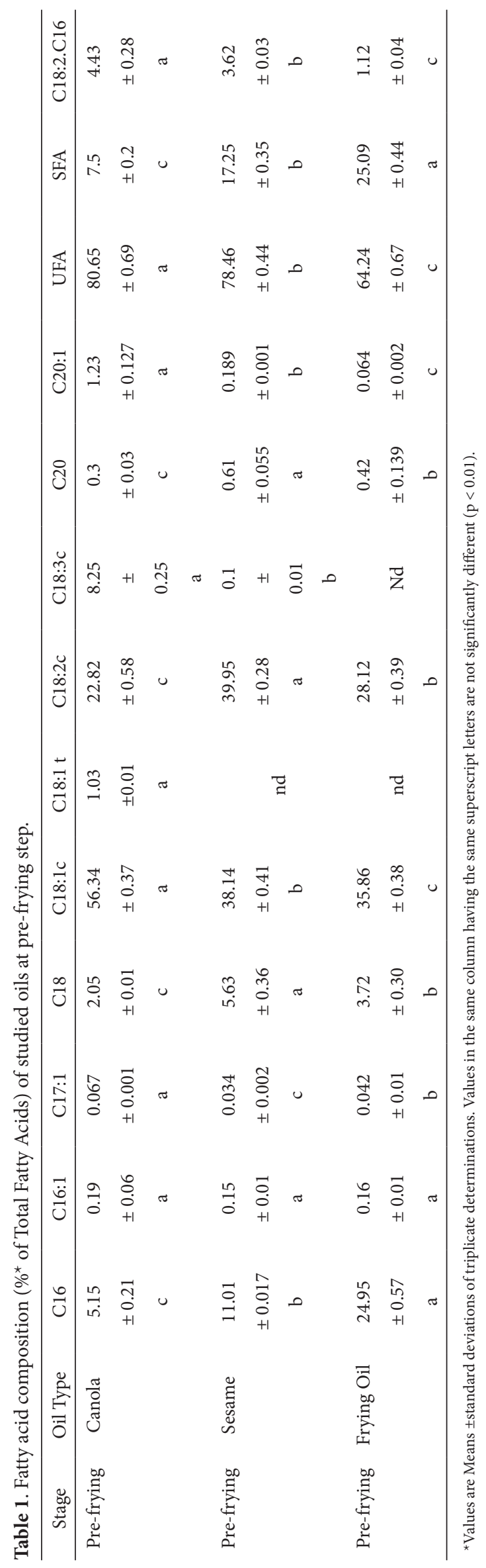


The range of DPPH was 41-58(\%). As the Table 3 shows, the percentage of DPPH in fresh onion is more than fresh potato.

\subsection{Analysis of fried potatoes}

\subsubsection{Fat, moisture and fiber content of fried potato}

Table 4 indicates the amount of fat, moisture and fiber of fried potato in canola oil, sesame oil and frying oil at first and third steps.

The results given in Table 4 show that the range of fat content for fried potato was $12-15.5 \%$ at first and third step of frying. The highest fat gain in the fried potato at two steps is corresponded to canola oil, frying oil and sesame oil, respectively. At third step, fried potato has absorbed more fat than first step of frying. As the Table 5 shows, there was significant difference between fried potatoes in terms of gained fat $(p<0.01)$.

In contrast, the percentages of moisture fell in both steps of frying. The range of water amount was $51-60 \%$ at two steps. The highest moisture was found in fried potato with frying oil, sesame oil and canola oil, respectively at two steps. As the Table 4 shows, there was significant difference in terms of water amount $(\mathrm{p}<0.01)$.

Table 2. The amount of total tochopherol and DPPH in pre-frying steps of Canola oil, Sesame oil and Frying oil.

\begin{tabular}{cccc}
\hline \multirow{2}{*}{ Stage } & Oil Type & $\begin{array}{c}\text { Total tochopherol } \\
(\mathrm{mg} . \mathrm{kg})^{*}\end{array}$ & DPPH \\
\hline Pre- & Canola & 237.60 & $(\%)^{*}$ \\
frying & & \pm 17.97 & 47.30 \\
& & $\mathrm{c}$ & \pm 0.42 \\
Pre- & Sesame & 319.70 & $\mathrm{c}$ \\
frying & & \pm 14.11 & 61.7 \\
& & $\mathrm{a}$ & \pm 0.39 \\
Pre- & Frying & 274 & $\mathrm{a}$ \\
frying & Oil & $6 \pm$ & 53.8 \\
& & $\mathrm{~b}$ & \pm 0.47 \\
\hline
\end{tabular}

*Values are Means \pm standard deviations of triplicate determinations. Values in the same column having the same superscript letters are not significantly different $(\mathrm{p}<0.01)$.

Table 3. Amount of fat, moisture, fiber DPPH of crude potato and onion.

\begin{tabular}{|c|c|c|c|c|c|}
\hline \multirow{2}{*}{ Stage } & \multirow{2}{*}{ Vegetable } & Fat & Moisture & Fiber & DPPH \\
\hline & & $(\%)^{*}$ & $(\%)^{*}$ & $(\%)^{*}$ & $(\%)^{*}$ \\
\hline \multirow[t]{3}{*}{ Raw } & Potato & 0.05 & 72.15 & 13.83 & 41.6 \\
\hline & & \pm 0.01 & \pm 0.2 & \pm 0.29 & \pm 0.34 \\
\hline & & $\mathrm{a}$ & $\mathrm{b}$ & $\mathrm{a}$ & $\mathrm{b}$ \\
\hline \multirow[t]{3}{*}{ Raw } & Onion & 0.03 & 89.04 & 4.18 & 57.4 \\
\hline & & \pm 0.003 & \pm 0.2 & \pm 0.31 & \pm 0.43 \\
\hline & & $\mathrm{a}$ & $\mathrm{a}$ & $\mathrm{b}$ & $\mathrm{a}$ \\
\hline
\end{tabular}

*Values are Means \pm standard deviations of triplicate determinations. Values in the same column having the same superscript letters are not significantly different $(\mathrm{p}<0.01)$.
In comparison to the raw vegetables, the percentage of water in fresh crops was more than fried food. According the results of Ramírez-Anaya et al. (2015) and Chiou et al. (2009), frying is a dehydration technique that the water of foods evaporated.

The results in Table 4 indicate that the percentage of fiber was 1-1.4. At first and third steps of frying, the most fiber is belonged to fried potato with frying oil, sesame oil and canola oil, respectively. As the Table 5 shows, there was no significant difference between fried potatoes in terms of fiber amount $(p<0.01)$. The amount of fiber in fresh potato was more than fried potato.

\subsubsection{Fatty acids analysis of fried potato}

Table 5 indicates the fatty acid composition (FFA) of oils at the first and the third stages of frying potatoes.

Oleic and linoleic acid were predominant, palmitic and stearic acids, and some of them were present at lower concentrations.

The ranges of palmitic acid at both steps of frying for fried potato in the three oils were $5-27.5 \%$. The order of the oils with regard to C16:0 content was as fallows; frying oil, sesame oil and canola oil. These fried potatoes were significantly different with regard to their C16:0 content $(\mathrm{p}<0.05)$, but there were not between first and second steps of frying. It should be noted that the amount of this compound at fried sesame oil was reduced and in fried canola and frying oil increased rather than un-fried oils.

Table 4. The fat, moisture and fiber content of fried potato at first and third steps.

\begin{tabular}{|c|c|c|c|c|}
\hline \multirow{2}{*}{ Stage } & \multirow{2}{*}{ Oil Type } & Moisture & Fat & Fiber \\
\hline & & $(\%)^{*}$ & $(\%)^{*}$ & $(\%)^{*}$ \\
\hline \multirow{3}{*}{ Frying1 } & Canola & 51.6 & 14.89 & 1.2 \\
\hline & & \pm 0.37 & \pm 0.38 & \pm 0.16 \\
\hline & & d & $\mathrm{a}$ & $\mathrm{a}$ \\
\hline \multirow[t]{3}{*}{ Frying1 } & sesame & 55.6 & 12.20 & 1.3 \\
\hline & & \pm 0.34 & \pm 0.33 & \pm 0.19 \\
\hline & & c & $\mathrm{d}$ & $\mathrm{a}$ \\
\hline \multirow[t]{3}{*}{ Frying1 } & frying oil & 59.9 & 12.95 & 1.35 \\
\hline & & \pm 0.24 & \pm 0.24 & \pm 0.12 \\
\hline & & $\mathrm{a}$ & c & a \\
\hline \multirow[t]{3}{*}{ Frying 3} & canola & 51.7 & 15.4 & 1.1 \\
\hline & & \pm 0.2 & \pm 0.26 & \pm 0.08 \\
\hline & & d & $\mathrm{a}$ & $\mathrm{a}$ \\
\hline \multirow[t]{3}{*}{ Frying 3} & sesame & 55.7 & 12.5 & 1.2 \\
\hline & & \pm 0.92 & \pm 0.55 & \pm 0.108 \\
\hline & & c & $c, d$ & a \\
\hline \multirow[t]{3}{*}{ Frying 3} & frying oil & 58.5 & 13.8 & 1.27 \\
\hline & & \pm 0.53 & \pm 0.31 & \pm 0.16 \\
\hline & & $\mathrm{b}$ & $\mathrm{b}$ & $\mathrm{a}$ \\
\hline
\end{tabular}

*Values are Means \pm standard deviations of triplicate determinations. Values in the same column having the same superscript letters are not significantly different $(\mathrm{p}<0.01)$. 


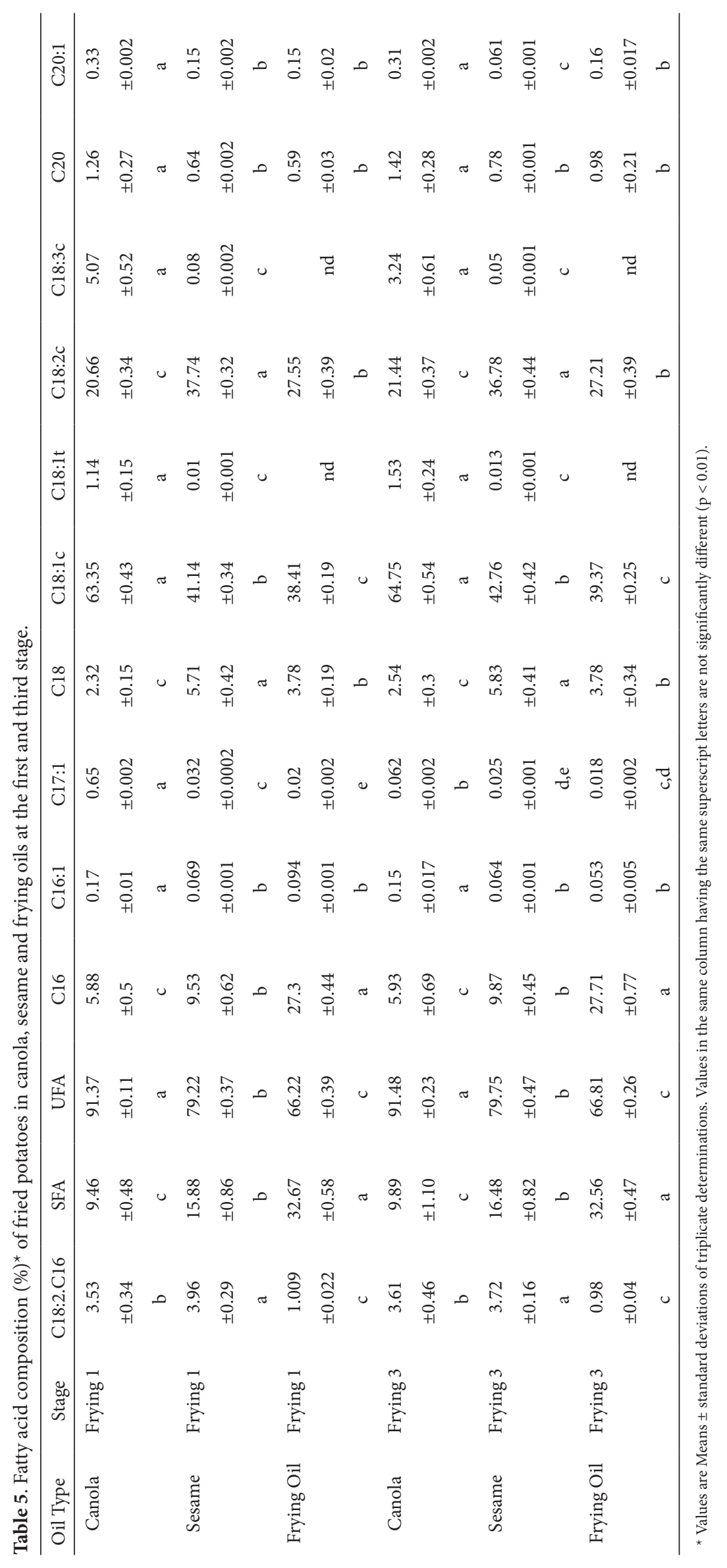


The Oleic acid content was $38-65 \%$ for fried potatoes at two steps. The highest amount of this FA was found in canola oil, sesame oil and frying oil, respectively. The fried oils were significantly different with regard to their C18:1c content $(\mathrm{p}<0.05)$, but there were not between first and second steps of frying. The amount of this fatty acid in fried oils has increased in comparison to all three un-fried oils.

Despite of a significant difference among oils in terms of C18: 1, there is no significant difference between steps frying for each oil. The amount of this fatty acid in fried oils has increased compared to all three non-fried oils. The reason for the increase of this fatty acid with a double bond can be attributed to the thermal degradation of linoleic acid (two unsaturated bonds) and linolenic acid (three unsaturated bonds) and also the increase in the ratio of oleic acid in the oil composition (Saghaei and Piravi Vanak, 2018).

The range of linoleic acid was $20-38 \%$ in fried potatoes in the three oils at first and third steps. The highest amount of this compound was observed in sesame oil, followed by frying oil and canola oil. The fried oils were significantly different with regard to their $\mathrm{C} 18: 2 \mathrm{c}$ content $(\mathrm{p}<0.05)$, but there were not between first and second steps of frying. Also, the amount of this compound in fried oils compared with non-fried oil, has shown a decreasing trend.

There is a significant difference between the three oils in terms of C18: 2, but no significant difference was observed between the first and the third stage of frying between each oil, except for frying oil. It should be noted that the amount of this compound in fried oils compared to non-fried oils has shown a decreasing trend. This decrease is probably due to the degradation of dual unsaturated bonds due to the deep frying process and its conversion into oxidation products, resulting in a decrease in the amount of unsaturated fatty acids and an increase in the ratio of saturated fatty acids (Saghaei and Piravi Vanak, 2018). The results obtained from the effect of deep frying process on the fatty acid composition of grape seed oil by Saghaei and Piravi in 1398 were also consistent with the results of the present study.

Linoleic and linolenic unsaturated fatty acids are important compounds that are affected by chemical reactions during frying. These changes in the amount and structure of fatty acids are directly related to time and temperature (Warner, 2004).

The range of saturated fatty acid (SFA) at two steps was 9-34\%. The highest amount of SFA at first and second step was found in frying oil, sesame oil and canola oil, respectively. It observed that the amount of saturation in fried oils has been shown to increase in oils comparison with un-fried oils. But it should be mentioned that the lowest changing in saturated free fatty acids is belonged to sesames oil.

The range of unsaturated fatty acid (UFA) content was $66-92 \%$ at first and third steps of frying. Considering the UFA content, the oils were ranked in increasing order as follows; canola oil, sesame oil and frying oil. The oils were significantly different with regard to their UFA content $(p>0.05)$ at first and second steps of frying. The amount of un-saturation in fried oils has shown an increasing trend compared to primary oils.
Serjouie et al. (2010) studied the effect of frying process on fatty acid composition and iodine value of selected vegetable oils and their composition. Six frying samples were considered as the main treatments: Palm oleine. Sesame Oil (AB, 1: $1 \mathrm{w} / \mathrm{w})$, RBD Palm oleine (RBD), Palm oleine (A), Canola Oil (C), Palm Olein oil . Sesame Oil, Palm Oil, Sesame Oil . Canola Oil (BC, 1: 1, w/w) and RBD Palm Oil . Sesame Oil . Canola oil. The analysis of fatty acids showed that the amount of linolenic acid (C18:3) and linoleic acid (C18:2) decreased while palmitic acid (C16:0) increased with frying time, which it is similar with the results of this study. Serjouie et al attributed the decrease in linolenic acid and the increase in palmitic acid to oil oxidation and oxygen uptake during frying. They also reported that the rate of oxygen uptake and the reaction between $\mathrm{O} 2$ and fatty acid C18, C18: 1 and C18: 2 were $1.2 \times 10^{4}, 5.3 \times 10^{4}, 7.3 \times 10^{4}$ and $10 \times 10^{4}\left(\mathrm{M}^{-1} \mathrm{~S}^{-1}\right)$, respectively. As it is known, the reaction rate of C18: 3 with oxygen is much faster than that of C18: 2 and C18: 1, so the highest decrease was observed at C18: 3 and the lowest decrease at C18: 1 . The increase in $\mathrm{C} 18$ and $\mathrm{C} 16$ has also been attributed to the double and triple band breaks in the UFAS, which can be transferred to the same FAS or a shorter branch.

The formation of trans fatty acids in edible oils during the frying and heating process was evaluated by Tsuzuki et al. In this study, chopped potatoes (10\% frying oil (w/w) in canola oil used were fried at 160,180 and $200{ }^{\circ} \mathrm{C}$ and 10 frying cycles. They found that the fat content of crude potatoes was about $0.1 \%(\mathrm{w} / \mathrm{w})$ and the TFAs in crude potatoes were negligible. Therefore, fried potatoes contained lipids at the level of 8.8-2.9\% and their fatty acid composition was more consistent with frying oil. Their results showed that a typical frying process using non-hydrogenated edible oils had little effect on the absorption of TFA from edible oils.

The linoleic to palmitic acid ratio for these oils was 1-4\%. The highest amount of C18:2/C16 were corresponded to sesame oil, canola oil and frying oil, respectively. The oils were significantly different with regard to this ratio $(\mathrm{p}<0.05)$, but there were not between first and second steps of frying. The amount of C18:2/ C16 in fried oils has been shown to be a decreasing trend in fired sesame oil, and a decreasing trend in the canola oil and frying oil.

In a study by Serjouie et al. (2010), the C18: 2 /C16 ratio was also investigated. In the C18: 2.C16 ratio, C18: 2 and C16 fatty acids are commonly used as an indicator to identify the degree of fat degradation because linoleic acid is much more sensitive to oxidation while $\mathrm{C} 16$ is more stable. This ratio is used to identify the degree of oxidative deterioration in fried oil samples.

\subsubsection{Total Tochopherol and DPPH Analysis of Fried Potato}

The antioxidant activity of fried potato was determined with the DPPH. The range of DPPH was $41-54(\%)$ at first step and $32-41 \%$ at third step of frying. As the Table 6 show, the percentage of DPPH in fried potato at first step of frying is more than third step. The highest percentage of DPPH was corresponded to fried potato with sesame oil, frying oil and canola oil, respectively at two steps. It can be seen that the antioxidant capacity of the fried foods increased when sesame oil is used. The fried potato was not significantly different in this respect $(\mathrm{p}<0.01)$. All of used 
Table 6. Total Tochopherolcontent and DPPH account of fried potato at first and third step.

\begin{tabular}{lccc}
\hline \multirow{2}{*}{ Stage } & Oil Type & $\begin{array}{c}\text { Total tochopherol } \\
(\mathrm{mg} . \mathrm{kg})^{*}\end{array}$ & $\mathrm{DPPH}$ \\
\hline Frying1 & Canola & 183 & $(\%)^{*}$ \\
& & \pm 5.56 & 41.8 \\
Frying1 & sesame & 265 & \pm 0.44 \\
& & $6 \pm$ & $\mathrm{c}$ \\
& & $\mathrm{c}$ & 54.2 \\
Frying1 & frying oil & 238 & \pm 0.57 \\
& & \pm 6.08 & $\mathrm{a}$ \\
& & $\mathrm{b}$ & 45.4 \\
Frying 3 & canola & 79 & \pm 0.37 \\
& & \pm 5.56 & $\mathrm{~b}$ \\
& & $\mathrm{e}$ & 32.1 \\
Frying 3 & sesame & 179 & \pm 0.29 \\
& & \pm 6.55 & $\mathrm{e}$ \\
& & $\mathrm{c}$ & 41.7 \\
& & 133 & $\mathrm{~d}$ \\
\hline
\end{tabular}

*Values are Means \pm standard deviations of triplicate determinations. Values in the same column having the same superscript letters are not significantly different $(\mathrm{p}<0.01)$.

oils in this study increased the antioxidant capacity at first step of frying rather than raw step. As Ramirez-Anaya et al reported, there is a positive correlations total poly phenol content with $\mathrm{DPPH}$ (antioxidant capacity) in potato.

Also, the range of total tochopherol was 79-265 mg.kg. The fried potatoes were significantly different in the total tochopherol content $(\mathrm{p}<0.01)$. The highest amount of total tochopherol was observed in sesame oil followed by frying oil and canola oil.

\subsection{Analysis of fried onion}

\subsubsection{Fat, moisture and fiber content of fried onion}

Table 7 indicates the percentage of fat, moisture and fiber of fried onion at first and third steps of frying.

The results given in Table 7 indicate that the range of fat content of fried onion was 32-48\% in first and third step. Considering the gained fat, the fried onions were ranked in decreasing as follows; canola oil > frying oil > sesame oil at both steps of frying. As the Table 6 shows, there was significant difference between fried onion in terms of the fat content $(p<0.01)$.

Also, Table 7 shows that the range of moisture was $7-31 \%$ and 6-30.3\% at first and third step, respectively. The highest percentage of moisture was corresponded to fried onion with frying oil, sesame oil and canola oil, respectively at both steps. So, the percentage
Table 7. The fat, moisture and fiber content of fried onion at first and third steps.

\begin{tabular}{|c|c|c|c|c|}
\hline \multirow{2}{*}{ Stage } & \multirow{2}{*}{ Oil Type } & Moisture & Fat & Fiber \\
\hline & & $(\%)^{*}$ & $(\%)^{*}$ & $(\%)^{*}$ \\
\hline \multirow[t]{3}{*}{ Frying 1} & Canola & 7.3 & 47.8 & 3.1 \\
\hline & & \pm 0.39 & \pm 0.41 & \pm 0.07 \\
\hline & & $\mathrm{a}$ & $\mathrm{a}$ & c \\
\hline \multirow[t]{3}{*}{ Frying 1} & Sesame & 14.3 & 32.2 & 5.16 \\
\hline & & \pm 0.37 & \pm 0.39 & \pm 0.23 \\
\hline & & b & $\mathrm{d}$ & $\mathrm{a}$ \\
\hline \multirow[t]{3}{*}{ Frying 1} & Frying & 31.2 & 43.9 & 1.8 \\
\hline & & \pm 0.64 & \pm 0.4 & \pm 0.13 \\
\hline & & c & c & $\mathrm{d}$ \\
\hline \multirow[t]{3}{*}{ Frying 3} & Canola & 6.7 & 47 & 3.9 \\
\hline & & \pm 0.32 & \pm 0.27 & \pm 0.17 \\
\hline & & $\mathrm{a}$ & $\mathrm{b}$ & $\mathrm{b}$ \\
\hline \multirow[t]{3}{*}{ Frying 3} & Sesame & 13.9 & 32.7 & 4.9 \\
\hline & & \pm 0.28 & \pm 0.26 & \pm 0.27 \\
\hline & & $\mathrm{b}$ & $\mathrm{d}$ & $\mathrm{a}$ \\
\hline \multirow[t]{3}{*}{ Frying 3} & Frying & 30.25 & 40.9 & 2 \\
\hline & Oil & \pm 0.39 & \pm 0.38 & \pm 0.15 \\
\hline & & $\mathrm{d}$ & c & $\mathrm{d}$ \\
\hline
\end{tabular}

* Values are Means \pm standard deviations of triplicate determinations. Values in the same column having the same superscript letters are not significantly different $(\mathrm{p}<0.01)$.

of moisture went down in both steps of frying rather than raw onion. As the Table 6 shows there was significant difference in terms of the water percentage $(\mathrm{p}<0.01)$. The results were same with fried potato at this research and Ramírez-Anaya et al. (2015).

The results in Table 7 indicate that the amount of fiber was $1-5 \%$ at first and $2-5 \%$ at third steps of frying. The highest fiber was found in fried onion with sesame oil, canola oil and frying oil, respectively. As the Table 6 shows, there was significant difference fried onion in terms of the fiber account $(\mathrm{p}<0.01)$.

The percentage of fiber in raw onion was more than fried onion as same as potato.

\subsubsection{Fatty acids analysis of fried onion}

Table 8 observed the FA composition (FFA) of fried onion in the three oils at the first and third frying steps.

The result given in Table 8 show that in all fried onion, at the first and third step of frying, the highest amount of FAs belonged to oleic acid, linoleic acid, palmitic acid and stearic acid, but in sesame oil the highest amount of free fatty acids are linoleic acid, oleic acid, palmitic acid and stearic acid, respectively. In frying oil and canola oil the highest amount 
Nikzad et al.

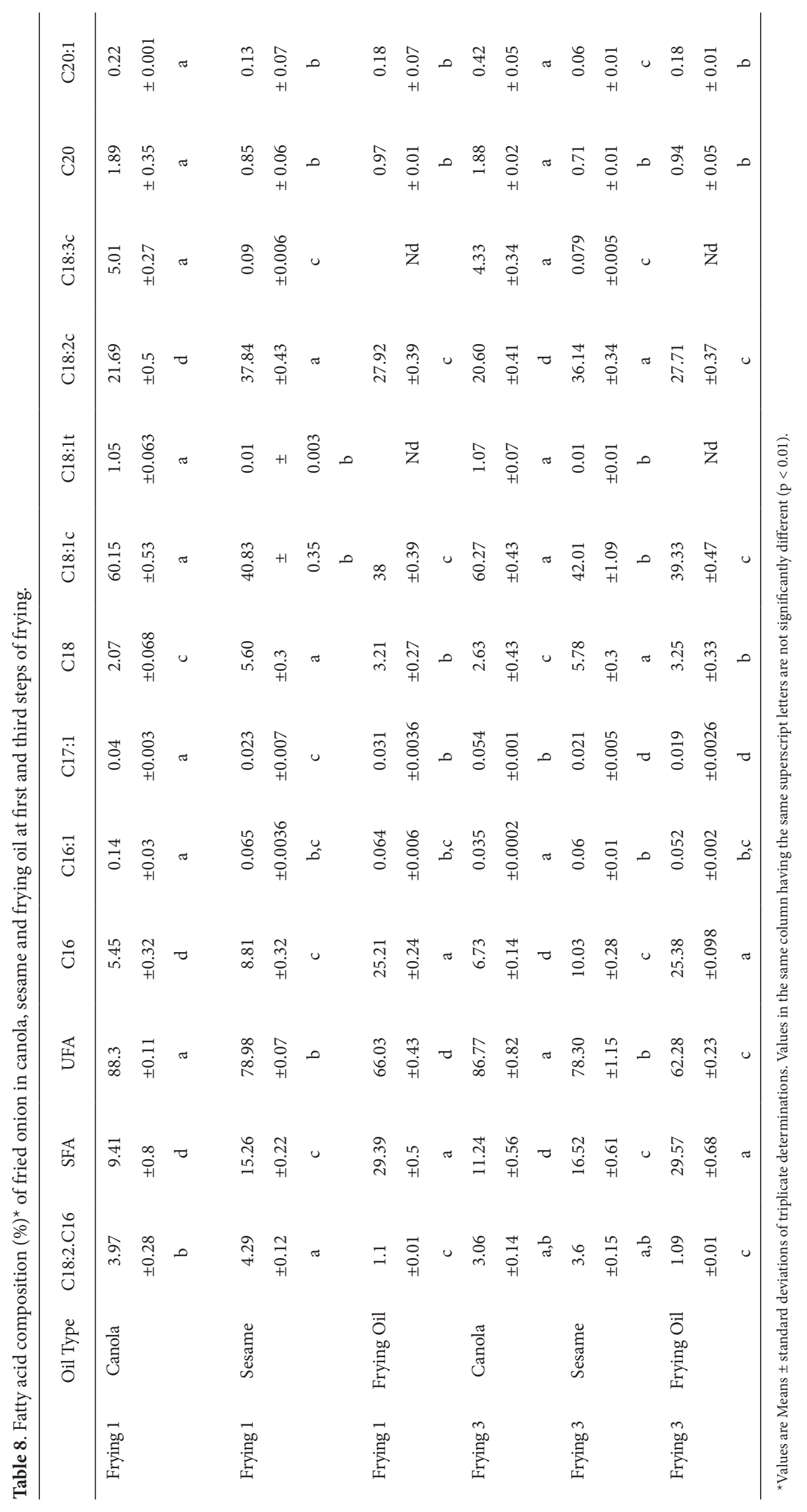


Table 9. Total Tochopherol and DPPH content of fried Onion at first and third step.

\begin{tabular}{|c|c|c|c|}
\hline \multirow{2}{*}{ Stage } & \multirow{2}{*}{ Oil Type } & Total Tochopherol & $\mathrm{DPPH}$ \\
\hline & & $(\mathrm{mg} \cdot \mathrm{kg})^{*}$ & $(\%)^{*}$ \\
\hline \multirow[t]{3}{*}{ Frying 1} & \multirow[t]{3}{*}{ Canola } & 174 & 51.32 \\
\hline & & \pm 4.48 & \pm 0.3 \\
\hline & & c & c \\
\hline \multirow[t]{3}{*}{ Frying 1} & \multirow[t]{3}{*}{ Sesame } & 292 & 58.8 \\
\hline & & \pm 4.48 & \pm 0.4 \\
\hline & & $\mathrm{a}$ & $\mathrm{a}$ \\
\hline \multirow[t]{3}{*}{ Frying 1} & \multirow{3}{*}{$\begin{array}{l}\text { Frying } \\
\text { Oil }\end{array}$} & 258 & 54.7 \\
\hline & & \pm 4.48 & \pm 0.36 \\
\hline & & $\mathrm{b}$ & $\mathrm{b}$ \\
\hline \multirow[t]{3}{*}{ Frying 3} & \multirow[t]{3}{*}{ Canola } & 54 & 28.4 \\
\hline & & \pm 4.48 & \pm 0.42 \\
\hline & & $\mathrm{f}$ & $\mathrm{f}$ \\
\hline \multirow[t]{3}{*}{ Frying 3} & \multirow[t]{3}{*}{ Sesame } & 147 & 39.1 \\
\hline & & \pm 4.48 & \pm 0.46 \\
\hline & & d & $\mathrm{d}$ \\
\hline \multirow[t]{3}{*}{ Frying 3} & \multirow{3}{*}{$\begin{array}{l}\text { Frying } \\
\text { Oil }\end{array}$} & 104 & 39.1 \\
\hline & & \pm 4.48 & \pm 0.46 \\
\hline & & $\mathrm{e}$ & $\mathrm{e}$ \\
\hline
\end{tabular}

*Values are Means \pm standard deviations of triplicate determinations. Values in the same column having the same superscript letters are not significantly different $(\mathrm{p}<0.01)$.

of FFAs are oleic acid, linoleic acid, palmitic acid and stearic acid, respectively.

The range of Palmitic acid in fried onion at both steps of frying was $5-26 \%$. The highest amount of this FA was found in frying oil, sesame oil and canola oil, respectively. These fried onions were significantly different with regard to their C16:0 content $(p<0.05)$, but there were not between first and second steps of frying except frying oil. It should be noted that the amount of this compound in fried oils increased in comparison with non-fried except sesame oil.

The Oleic acid content was 39-60\% in fried oils of fried onion at two steps. The order of the oils with regard to this FA content was as fallows; in canola oil, sesame oil and frying oil. The fried oils were significantly different in fried oils at first step with regard to their C18:1c content $(p<0.05)$, but there were not significantly differences between first and second steps of frying. The amount of this fatty acid in fried oils has increased in comparison to all three unrefined oils.

The range of linoleic acid was $22-38 \%$ in fried potatoes at first and third steps. The highest amount of linoleic acid was found in sesame oil, frying oil and canola oil, respectively. The oils were significantly different with regard to their $\mathrm{C} 18: 2 \mathrm{c}$ content $(\mathrm{p}<0.05)$, but there were not significantly differences between each oil except frying oil during two steps. Also, the amount of this compound in fired oils, as compared to non-fried oil has been decreased.

The range of saturated fatty acid (SFA) at two steps of frying was $9-30 \%$. Considering the SFA content, the oils were ranked as follows; frying oil, sesame oil and canola oil at two steps of frying. These fried onions were significantly different with regard to their SFA content $(\mathrm{p}<0.05)$ at first and second steps of frying. The amount of saturation in fried oils has shown an increasing trend compared to un-fried oils.

The range of unsaturated fatty acid (UFA) content was 62-90\% at first and third steps of frying. The highest amount of UFA in fried onion was found in canola oil, followed by sesame oil and frying oil at first and third steps of frying. These fried onions were significantly different with regard to their SFA content $(\mathrm{p}<0.05)$ at two steps of frying. Also, the amount of non-saturation in fried oils has shown a decreasing trend compared to un-fried oils.

The ratio of C18:2./C16 for these oils was $1-4 \%$. The highest amount was corresponded to sesame oil, canola oil and frying oil, respectively. The oils were significantly different with regard to this ratio $(p<0.05)$ at first step of frying, also there were no difference between first and second steps of frying. It should be noted that the amount of this ratio have not change significantly during frying.

\subsubsection{Total tochopherol and DPPH analysis of fried onion}

The range of DPPH was 51-59(\%) and 28-39\% at first and third step of frying, respectively. As the Table 9 shows, the percentage of DPPH in fried onion at first step of frying is more than third step. The ranking of the fried onion with regard to percentage of DPPH was as follows; sesame oil > frying oil > canola oil at both steps of frying. The fried potato was not significantly different in this respect $(\mathrm{p}<0.01)$. In spite on increasing total poly phenol, the percentage of DPPH of fried onions was lower than raw onions. In this study, there was not the correlation between $\mathrm{DPPH}$ and total poly phenol among fried onion, whereas on other studies it has been high.

The DPPH content of the raw onion extract is higher than canola oil and frying oil, therefore, after frying, it has not been able to increase DPPH levels, such as potatoes. But DPPH of sesame oil was higher than raw onion extract, which increased after frying.

The range of total tochopherol was 174-292 mg.kg for the first step and 54-147 mg.kg for the second step. The fried onions were significantly different in the total tochopherol content $(\mathrm{p}<0.01)$. The highest amount of total tochopherol was observed in sesame oil followed by frying oil and canola oil.

\section{Conclusion}

In deep frying, oil is heated for a long time and due to factors such as moisture, heat and oxygen, it causes various physical and chemical changes such as hydrolysis, oxidation and polymerization in the oil and reduces its quality and final product. Research shows that the chemical composition of oils, and especially the amount of natural antioxidants, is an important indicator in predicting the behavior of oils in the frying process.

Researches show that the chemical composition of the oils, and especially the amount of natural antioxidants, is an important indicator in predicting oil behavior in the frying process. In this study, the oxidative stability of sesame, canola and frying oils during frying was compared with respect to the presence of natural bioactive compounds (antioxidants) and fatty acid composition. The most important compounds that cause oxidative resistance of oil are alpha-tocopherol, phenols and mainly monounsaturated fatty acids. Canola oil, although is cheap and have vitamin E, but because of lacking important 
bioactive compounds and the nature of its unsaturated fatty acids, is very sensitive to oxidation.

Due to the changes in fatty acid profile in fried samples, the amount of linolenic acid in fried samples in sesame and canola decreased but was not changed in frying oil.

Trans fatty acids are found in canola oil and sesame oil, although the amount of them in sesame oil is very low. Also, frying oil does not contain trans, which can be attributed to the presence of antioxidants that are added manually to the oil. The trend of changes of other fatty acid compounds in each sample was different depending on the resistance of the oil sample. In fried onions, the amount of trans fatty acids formed is lower than in fried potatoes, which can be attributed to the difference in frying time.

In terms of tocopherol and DPPH, the highest amounts were observed in fried vegetables with sesame oil and fried oil and canola oil, respectively. Finally, considering to the absence of synthetic antioxidant in sesame oil, this oil has shown a better result in terms of resistance to deep frying and has the least changes in fatty acids profile.

\section{References}

Association of Official Analytical Chemists - AOAC (1995). In: Cunniff, P. (Ed.), Official Methods of Analysis of AOAC.International (16th ed.) USA: AOAC International.

Bakhtiary, D., Asadollahi, S., \& Yasini Ardakani, S.A., (2014). Sensory qualities of sesame oil, palm Olein and the blend of them during frying of potato chips. International Juornal of Farming and Allied Sciences, 3(7), 786-790.

Beig Mohammadi, Z., Maghsoudlou, Y., Safafar, H., \& Sadeghi Mahoonak, R. (2012). Physicochemical properties and stanility of oil extracted from three canola cultivars grown in golestan province of Iran. Journal of Agricultural Science and Technology, 14, 577-586.

Borjian Borojeni, M., Goli, S. A. H., \& Gharachourloo, M. (2016). Effect of roasted sesame oil on qualitative properties of frying oil during deep-fat frying. Journal of Agricultural Science and Technology, 18, 1531-1542.

Burlingame, B., Mouillé, B., \& Charrondière, R. (2009). Nutrients, bioactive non-nutrients and anti-nutrients in potatoes. Journal of Food Composition and Analysis, 22(6), 494-502. http...dx.doi. org.10.1016.j.jfca.2009.09.001.

Chiou, A., Kalogeropoulos, N., Salta, F. N., Efstathiou, P., \& Andrikopoulos, N. K. (2009). Pan-frying of French fries in three different edible oils enriched with olive leaf extract: Oxidative stability and fate of microconstituents. Lebensmittel-Wissenschaft + Technologie, 42(6), 1090-1097. http:..dx.doi.org.10.1016.j.lwt.2009.01.004.

Choe, E., \& Min, D.B. (2007). Chemistry of deep-fat frying oils. Journal of Food Science, 72(5), R77-86.

Chung, J., Lee, J., \& Choe, E. (2004). Oxidative stability of soybean and sesame oil mixture during frying of flour dough. Journal of Food Science, 69(7), 574-578. http:..dx.doi.org.10.1111.j.1365-2621.2004.tb13652.x.

Farhoosh, R., \& Esmaeilzadeh Kenari, R. (2009). Anti-rancidity effects of sesame and rice bran oils on canola oil during deep frying. Journal of the American Oil Chemists' Society, 86(6), 539-544. http:..dx.doi. org.10.1007.s11746-009-1382-7.

Gharby, S., Harhar, H., Bouzoubaa, Z., Asdadi, A., El Yadini, A., \& Charrouf, Z. (2015). Chemical characterization and oxidative stability of seeds and oil of sesame grown in Morocco. Journal of the Saudi Society of Agricultural Sciences, 16(2), 105-111. http://dx.doi.org/10.1016/j. jssas.2015.03.004.

Ghidurus, M., Turtoi, M., Boskou, G., Niculita, P., \& Stan, V. (2010). Nutritional and health aspects related to frying. Romanian Biotechnological Letters, 15(6), 2010.
Gol Ahmad M., Hojjatoleslami M., Jafari M., Sedaghat Boroujeni L., (2019). Evaluation of chemical compounds and antioxidant properties of Paghazeh and Syrian Walk plants on soybean oil. Herbal Drugs, 10(2), 35-47.

International Organization for Standardization - ISO. (2006). ISO 9936:2006: Animal and vegetable fats and oils - Determination of tocopherol and tocotrienol contents by high-performance liquid chromatography. Geneva, Switzerland: ISO.

International Organization for Standardization - ISO. (2016). Animal and vegetable fats and oils- Gas chromatography of fatty acid methyl esters- Part 4: Determination by capillary gas chromatography (1st ed.). Geneva, Switzerland: ISO.

Molyneux, Ph. (2004). The use of the stable free radical diphenylpicrylhydrazyl (DPPH) for estimating antioxidant activity Songklanakarin. Journal of Science and Technology, 26(2), 211-219.

Nikzad, N., Sahari, M., Ghavami, M., Piravi Vanak, Z., Hosseini, E., Safafar, H., \& Bolandnazar, A. (2013). Physico-chemical properties and nutritional indexes of cultivars during table olive processing. Iranian Journal of Food Science and Technology, 9(39), 31-41.

Nzikou, J. M., Matos, L., Bouanga-Kalou, G., Ndangui, C. B., PambouTobi, N. P. G., Kimbonguila, A., Silou, Th., Linder, M., \& Desobry, S. (2009). Chemical composition on the seeds and oil of sesame (Sesamum indicum L.) grown in Congo-Brazzaville. Advance Journal of Food Science and Technology, 1(1), 6-11.

Pedreschi, F., Cocio, C., Moyano, P., \& Troncoso, E. (2008). Oil distribution in potato slices during frying. Journal of Food Engineering, 87(2), 200-212. http:..dx.doi.org.10.1016.j.jfoodeng.2007.11.031.

Petropoulos S.A., Fernandes, Â., Barros, L., Ferreira, I.C., \& Ntatsi, G. (2015). Morphological, nutritional and chemical description of "Vatikiotiko", an onion local landrace from Greece. Food Chemistry, 182:156-163. http:..dx.doi.org.10.1016.j.foodch em.2015.03.002.

Ramírez-Anaya, J. P., Samaniego-Sánchez, C., Castañeda-Saucedo, M. C., Villalón-Mir, M., \& de la Serrana, H. L, (2015). Phenols and the antioxidant capacity of Mediterranean vegetables prepared with extra virgin olive oil using different domestic cooking techniques. Food Chemistry, 188, 430-438. http...dx.doi.org.10.1016.j.foodch em.2015.04.124. PMid:26041214.

Saghaei, S., \& Piraki Vanak, Z. (2020). The effect of deep frying process on fatty acid compounds and sterols in grape seed oil. Journal of Food Science and Nutrition, 17(1), 49-62.

Sedaghat Boroujeni, L., Hojjatoleslami, M., Ghasemi Pirbalouti, A., \& Molavi, H. (2013). Phytochemistry analysis of essential oils of Heracleum lasiopetalum fruits, Thymus carmanicus aerial parts, and Myrtus communis leaves. J. Herbal drugs, 4(2), 101-108.

Sedaghat Boroujeni L., \& Hojjatoleslamy M.(2018). Using Thymus carmanicus and Myrtus communis essential oils to enhance the physicochemical properties of potato chips. Journal of Food Science. Food Science \& Nutrition, 6(4), 1006-1014.

Serjouie, A., Tan, C. P., Mirhosseini, H., \& Che Man, Y. B. (2010). Effect of frying process on fatty acid composition and iodine value of selected vegetable oils and their blends. International Food Research Journal, 17, 295-302.

Warner, K. (2004). Chemical and physical reactions in oil during frying. Frying technology and practice (pp. 16-28). Champaign: AOCS.

Wegener, Ch. B., Jansen, G., \& Jürgens, H. U. (2015). Bioactive compounds in potatoes: Accumulation under drought stress conditions. Functional Foods in Health and Disease, 5(3), 108-116. http:..dx.doi.org.10.31989.ffhd.v5i3.175.

$\mathrm{Wu}, \mathrm{W} . \mathrm{H}$. (2007). The contents of lignans in commercial sesame oils of Taiwan and their changes during heating. Food Chemistry, 104(1), 341-344. http:..dx.doi.org.10.1016.j.foodchem.2006.11.055.

Yen, G.-C., \& Shyu, S.-L. (1989). Oxidative stability of sesame oil prepared from sesame seed with different roasting temperatures. Food Chemistry, 31(3), 215-224. http:..dx.doi.org.10.1016.03088146(89)90059-9. 